\title{
GESTÃO PRIVADA NA SAÚDE PÚBLICA EM SÃO PAULO: UM ESTUDO DE CASO DA UTILIZAÇÃO DE ORGANIZAÇÃO SOCIAL DE SAÚDE
}

\author{
PRIVATE MANAGEMENT IN PUBLIC HEALTH IN SAO PAULO: \\ A CASE STUDY OF THE USE OF SOCIAL HEALTH ORGANIZATION
}

\author{
Jose Orcelio do Nascimento \\ Fundação Escola de Comércio Álvares Penteado, São Paulo, SP, Brasil. \\ E-mail: jorcelio@uol.com.br
}

Ribamar Antunes Pereira

Fundação Escola de Comércio Álvares Penteado, São Paulo, SP, Brasil. E-mail: ribbamar@hotmail.com

Marcus Vinicius Moreira Zittei

Fundação Escola de Comércio Álvares Penteado, São Paulo, SP, Brasil. E-mail:marcuszittei@zittei.com.br

Leonardo Fabris Lugoboni

Fundação Escola de Comércio Álvares Penteado, São Paulo, SP, Brasil. E-mail: leo_fabris@hotmail.com

Recebido em: 03.04.2017 - Aceito em: 15.07.2017

\section{RESUMO}

O modelo de Telerradiologia é viável para atender às unidades de saúde que ainda não utilizam essa tecnologia nos serviços médicos para todo o estado de São Paulo. Isso se deve ao interesse do Estado em investir na expansão desses serviços nas regiões em que se faz necessário, visando otimizar recursos tecnológicos e humanos, como, por exemplo, médicos radiologistas e técnicos em radiologia. O objetivo geral desta pesquisa foi investigar a eficiência da gestão privada no Sistema Único de Saúde em São Paulo, através dos serviços de diagnóstico por imagem. Foi realizada uma pesquisa de natureza qualitativa, exploratória e descritiva, por meio de um estudo de caso. O fato considerado relevante nesta pesquisa são os indicadores que demonstram o melhor custo-benefício aos cofres públicos e, mais ainda, a grande preocupação com a qualidade do diagnóstico à população, no menor tempo possível, visando a um atendimento humanizado e diminuindo as grandes filas de espera, seja no agendamento, seja na própria realização dos exames. O modelo representa o melhor custo-benefício encontrado na gestão por Organização Social de Saúde oferecido à população e ao governo do estado de São Paulo. 
PALAVRAS-CHAVE: Saúde pública; Organização Social de Saúde; Telerradiologia.

\section{ABSTRACT}

The Teleradiology model is feasible to meet the health units that do not yet use this technology in the medical services for the State of São Paulo that the State's interest in investing in the expansion of these services in the regions that are necessary, in order to optimize human and technological resources, as an example: radiologists and radiology technicians. The general objective of this research was to investigate the efficiency of private management in the health system in São Paulo, through diagnostic imaging services. A research of qualitative, exploratory, descriptive nature through a case study. The fact considered relevant in this research are the indicators that demonstrate the best cost-benefit to public coffers and more still in great concern with the quality of the diagnosis to the population, in the shortest time possible, aiming a humanized, decreasing the large queues, is on schedule as on own exams. The best cost-benefit ratio found in the Social organization of Health management offered to the people and the Government of the State of São Paulo.

KEYWORDS: Public health; Social Health Organization; Teleradiology.

\section{INTRODUÇÃO}

Nos últimos anos, houve uma iniciativa para criar a Nova Gestão Pública (NGP) no Brasil, como, por exemplo, o Ministério da Administração Federal e Reforma do Estado (MARE) e as Organizações Sociais de Saúde (OSS).

O modelo de OSS é uma iniciativa de delegação da gestão pública direta para a gestão privada, de forma que a população não seja prejudicada, tanto na assistência, ou seja, nos serviços prestados pelas OSS, quanto nos preços cobrados por estes serviços da Administração Pública. Assim, pode-se definir um modelo de gestão, estabelecendo critérios de monitoramento e controle dos gastos, através de estudos de viabilidade, o que garante maior transparência do fluxo de caixa com seus investimentos e maior ênfase nas auditorias, estabelecendo medidas punitivas.

Os objetivos apresentados no Plano Diretor da Reforma do Aparelho do Estado (PDRAE), formulado pelo Ministério da Administração Federal e Reforma do Estado de 1995, aponta o estado de São Paulo como a experiência na saúde por Organização Social que repassa os equipamentos sociais a entidades da sociedade civil. 
No desenho da NGP, a convergência principal se dá ao Estado de forma mais reguladora, buscando preferencialmente a desburocratização e descentralização e favorecendo o aumento da autonomia de gestão Bresser-Pereira (1998).

Os mecanismos de accountability nas OSS possibilitam ao Estado o acompanhamento das responsabilidades e obrigações das OSS pela legislação federal previamente estabelecida, no que se refere ao programa de trabalho, metas, prazos de execução, critérios objetivos de avaliação de desempenho que utilizem indicadores de qualidade e produtividade, limites para despesas com remuneração dos dirigentes e empregados.

A principal aliança entre o Estado e as OSS é pactuada através do Contrato de Gestão que é assegurado pelo artigo $6^{\circ}$ da Lei Complementar $n^{\circ}$ 846/1998:

Artigo $6^{\circ}$ - Para os efeitos desta lei complementar, entende-se por contrato de gestão o instrumento firmado entre o Poder Público e a entidade qualificada como organização social, com vistas à formação de uma parceria entre as partes para fomento e execução de atividades relativas à área da saúde ou da cultura.

$\S 3^{\circ}$ - A celebração dos contratos de que trata o 'caput' deste artigo, com dispensa da realização de licitação, será precedida de publicação da minuta do contrato de gestão e de convocação pública das organizações sociais, através do Diário Oficial do Estado, para que todas as interessadas em celebrá-lo possam se apresentar.

O modelo de contrato de gestão aplicado às entidades qualificadas para a gestão dos serviços públicos adota um formato de atuação diferente do que vem sendo desenvolvido pelo poder público, com o objetivo de trazer um novo paradigma de gestão privada, no que diz respeito à qualidade, agilidade, melhor custo, entre outros fatores que impactam no gerenciamento da máquina pública.

O objetivo geral desta pesquisa foi investigar a eficiência da gestão privada no Sistema Único de Saúde (SUS) em São Paulo, através dos serviços de diagnóstico por imagem.

Os serviços prestados pelas OSS consistem especificamente na realização de exames e laudos diagnósticos em: Ressonância Magnética, Tomografia Computadorizada, Mamografia, Ultrassonografia, Ultrassonografia com Doppler e Raios-x. Os exames oferecidos têm por objetivo atender à população usuária do SUS em algumas regiões do estado de São Paulo, com a qualidade compatível com os serviços particulares e convênios médicos, bem como oferecer outros diferenciais, relacionados ao menor tempo para emissão dos resultados já observados em serviços da mesma natureza.

O objetivo específico desta pesquisa foi investigar o modelo de Telerradiolo- 
gia que compõe imagens digitais com resultados mais precisos no menor tempo já realizado em serviços públicos. Esse serviço tem como diferenciais tecnologias inovadoras e profissionais qualificados para o bom funcionamento das atividades correlacionadas ao desempenho do objetivo principal, através dos modelos convencionais utilizados, os quais ficam submetidos à reestruturação, que garante à sociedade a evolução no tratamento médico e uma melhor gestão econômica.

A importância do tema desta pesquisa está em apresentar as experiências utilizadas pela gestão privada no estado de São Paulo aplicadas ao SUS, as quais visam atender à população usuária do serviço público no estado de forma humanizada, permitindo maior acesso aos recursos tecnológicos que asseguram maior qualidade no diagnóstico dos exames realizados, com menor tempo de espera, tanto para os agendamentos quanto para a realização dos exames e resultados.

A pesquisa apresentada avaliou como o Serviço Estadual de Diagnóstico por Imagem 1 (SEDI1), gerenciado pela Associação Congregação de Santa Catarina (ACSC), pode reduzir custos na saúde pública, na qual os recursos são cada vez mais escassos frente à grande demanda dos pacientes. Conforme a Constituição Federal de 1988:

Art. 196. A saúde é direito de todos e dever do Estado, garantido mediante políticas sociais e econômicas que visem à redução do risco de doença e de outros agravos e ao acesso universal e igualitário às ações e serviços para sua promoção, proteção e recuperação.

Até 2013, o SEDI1 realizava seus serviços em 11 unidades de saúde, cinco hospitais e seis ambulatórios, todos localizados na capital de São Paulo, com exceção de uma unidade (hospital) que está localizada em Américo Brasiliense (interior do estado, região de Araraquara). Considerando que há mais dois serviços com este modelo em São Paulo que atendem também aos usuários do SUS, o SEDI1 realiza uma volumetria significativa de exames superior à dos demais em virtude de ter sido pioneiro nessas atividades voltadas ao SUS em São Paulo.

O diagnóstico (laudo) é realizado através de uma central de laudos, por médicos radiologistas, com exceção dos exames de ultrassonografia, que são realizados e laudados por médicos no local onde o paciente se submete ao exame.

A questão de pesquisa deste artigo é: qual o impacto dos serviços de saúde prestados por OSS em relação ao custo-benefício na administração de unidade pública de saúde? 


\section{REFERENCIAL TEÓRICO}

\subsection{A reforma do Estado}

O Ministério da Administração Federal e Reforma do Estado, na década de 1990, recomendou a adoção de uma nova modalidade de gestão pública, que visava desenvolver uma característica de desempenho em que a sociedade pudesse usufruir dos seus direitos como cidadã e o estado, como dever, prestasse um serviço de qualidade na saúde, no que tange à maior flexibilidade gerencial, seja na aquisição de produtos e serviços, seja na gestão financeira, de forma que a aplicação dos recursos ocorresse de maneira que houvesse uma análise do custo-benefício, permitindo à sociedade o acesso, de forma transparente, aos gastos e a qualidade na satisfação dos usuários.

De acordo com Bresser-Pereira (1996), a crise do Estado e a necessidade de reforma levaram a uma reconstrução na qual se tornou imperativa a tarefa de redefinir suas funções. Os Estados podiam, antes da integração mundial dos mercados e dos sistemas produtivos, ter como um de seus objetivos fundamentais proteger as economias da concorrência mundial. Na saúde, educação, cultura, desenvolvimento tecnológico e investimentos em infraestrutura, a regulação e a intervenção continuam necessárias, considerando que não apenas compensam os desequilíbrios distributivos provocados pelo mercado globalizado, mas também figuram como principal agente econômico capacitado a competir internacionalmente.

No Brasil, podemos ver que o estado de São Paulo utilizou-se da reforma como possibilidade de mostrar, ou mesmo buscar, uma metodologia que garantisse o crescimento do país. Esse crescimento está baseado nas futuras gerações usuárias dos serviços públicos, de forma que a qualidade na assistência vem gradativamente evoluindo com as tecnologias, possibilitando diagnósticos mais precisos, no que tange ao conhecimento das causas que provocam consequências terríveis para a saúde do homem.

\subsection{As organizações sociais no setor de saúde pública}

A gestão no setor de saúde pública no estado de São Paulo por organizações sociais qualificadas visa promover, através da celebração do contrato de gestão, hipóteses de dispensa de licitação para contratação e outorga de permissão de uso público.

Para Medici e Murray (2010), os contratos de gestão asseguram o grau de responsabilidade e transparência no uso dos fundos públicos nas OSS. No mais, garantem mais autonomia na administração das entidades públicas em saúde, 
promovendo níveis elevados de eficiência e efetividade, em que as equipes de gestão buscam, com responsabilidade, atingir as metas de produção de serviços, bem como a qualidade e a satisfação dos usuários, permitindo, assim, facilitar as auditorias financeiras. A Secretaria Estadual de Saúde (SES), por exemplo, recebe relatórios mensais com custos de produção e estados financeiros de gastos que são declarados ao Tribunal de Contas do Estado, bem como à Secretaria da Fazenda, entre outras auditorias internas das próprias OSS.

Desde então, as instituições privadas consideradas filantrópicas, sem fins lucrativos na gestão dos serviços públicos, podem contribuir com o Estado no que tange a um complemento na evolução da qualidade dos serviços em saúde no SUS, e com previsão legal instituída na Constituição Federal.

Art. 197. São de relevância pública as ações e serviços de saúde, cabendo ao Poder Público dispor, nos termos da lei, sobre sua regulamentação, fiscalização e controle, devendo sua execução ser feita diretamente ou através de terceiros e, também, por pessoa física ou jurídica de direito privado. (Brasil, 1998, grifo nosso).

Art. 199. A assistência à saúde é livre à iniciativa privada.

$\S 1^{\circ}$ - As instituições privadas poderão participar de forma complementar do sistema único de saúde, segundo diretrizes deste, mediante contrato de direito público ou convênio, tendo preferência as entidades filantrópicas e as sem fins lucrativos. (Brasil, 1998, grifo nosso).

Como previsto na Lei Ordinária $n^{\circ} 8.080 / 1990$, que, na sua Ementa, dispõe sobre "as condições para a promoção, proteção e recuperação da saúde, a organização e o funcionamento dos serviços correspondentes e dá outras providências", a Disposição Preliminar do SUS prevê:

Art. $4^{\circ} \mathrm{O}$ conjunto de ações e serviços de saúde, prestados por órgãos e instituições públicas federais, estaduais e municipais, da Administração direta e indireta e das fundações mantidas pelo Poder Público, constitui o Sistema Único de Saúde (SUS). $\S 1^{\circ}$ Estão incluídas no disposto neste artigo as instituições públicas federais, estaduais e municipais de controle de qualidade, pesquisa e produção de insumos, medicamentos, inclusive de sangue e hemoderivados e de equipamentos para saúde. $\S 2^{\circ}$ A iniciativa privada poderá participar do Sistema Único de Saúde (SUS), em caráter complementar. (Brasil, 1990, grifo nosso).

A entidade é caracterizada como de interesse social e de utilidade pública, uma associação civil sem fins lucrativos, com atividades nas áreas de ensino, pesquisa científica, desenvolvimento tecnológico, proteção e preservação do meio ambiente, cultura e saúde, previstos na Lei Federal $n^{\circ}$ 9.637, de 15 de maio de 1998, que também estabelece outras responsabilidades: 
Da Execução e Fiscalização do Contrato de Gestão

Art. $8^{\circ} \mathrm{A}$ execução do contrato de gestão celebrado por organização social será fiscalizada pelo órgão ou entidade supervisora da área de atuação correspondente à atividade fomentada.

Da Desqualificação

Art. 16. O Poder Executivo poderá proceder à desqualificação da entidade como organização social, quando constatado o descumprimento das disposições contidas no contrato de gestão.

Segundo Médici e Murray (2010), as parcerias são feitas com instituições filantrópicas qualificadas, no caso as Organizações Sociais (OS) com reconhecida capacidade para administrar os hospitais. Os contratos de gestão são amplos e exigem a accountability com indicadores de avaliação.

Observando o período de 2000 a 2002, Ferreira Júnior (2003) constatou, nas OS, uma capacidade de produzir mais serviços sem grande variação financeira, em comparação com hospitais públicos de administração direta. Conforme o autor, houve um incremento significativo das internações e dos atendimentos ambulatoriais e de urgência por parte dos hospitais administrados por meio de contrato de gestão.

A utilização de ferramentas de gestão, como indicadores estratégicos e operacionais, e a elaboração de um planejamento estratégico baseado na metodologia Balanced Score Card e, quanto à gestão econômica e financeira, através da projeção orçamentária que visa demonstrar o controle do fluxo de caixa e acompanhar a movimentação do previsto $\times$ realizado, garantem uma saúde financeira mais sólida, para tomadas de decisões no menor tempo possível.

2.2.1 Serviço estadual de diagnóstico por imagem 1 - Associação Congregação de Santa Catarina/Organização Social de Saúde

Diante do avanço da tecnologia em diversas áreas, podemos notar na saúde a utilização de um Sistema de Arquivamento e Comunicação de Imagens, denominado Picture Archiving and Communication Systems (PACS). Esse sistema substitui a tradicional aquisição e armazenamento de filmes pelos departamentos de imagens pela aquisição e arquivamento digitais, que têm sido orientados pelos avanços na indústria da computação e na tecnologia de rede. Isso significa que, em vez de ter cópias radiográficas pesadas para processar, manipular, visualizar e armazenar, as imagens são cópias digitais leves processadas em um computador, vistas em um monitor e armazenadas eletronicamente. 
Uma rede de computadores chamada PACS foi criada para gerenciar esse tipo de imagem digital. O significado da sigla PACS é o seguinte: P - Picture: Imagem Clínica Digital; A - Archiving: Armazenamento (arquivamento) "eletrônico" das Imagens; C - Communication: Roteamento (recebimento/envio) e Exibição das Imagens; e S System: Rede Computadorizada Especializada que gerencia todo o sistema.

O PACS é uma sofisticada combinação de hardware e de software que conecta todas as modalidades que produzem imagens digitais (Medicina Nuclear, Ultrassonografia, Tomografia Computadorizada, Ressonância Magnética, Mamografia, Radiologia, Densitometria Óssea, entre outras imagens). A qualidade no diagnóstico que a tecnologia proporciona para o médico responsável na conclusão do laudo é reconhecidamente maior do que no modelo tradicional utilizado em entidades públicas que não possuem essas tecnologias.

\section{MÉTODO DE PESQUISA}

Esta pesquisa foi realizada junto ao Serviço Estadual de Diagnóstico por Imagem 1 (SEDI1), gerenciado pela Associação Congregação de Santa Catarina (ACSC), mostrando as características desse serviço, portanto este artigo tem natureza qualitativa. Conforme Marconi e Lakatos (2007), o método qualitativo se distingue pela forma de coleta e análise dos dados. Preocupa-se em interpretar e analisar aspectos mais profundos, descrevendo complexamente o comportamento humano. Além disso, analisa mais detalhadamente os hábitos, investigações, atitudes, tendências de comportamento, etc.

Já de acordo com Gil (2010), esse método retrata a maioria das pesquisas realizadas com propósitos acadêmicos, pelo menos num primeiro momento, considerando que é pouco provável que o pesquisador já tenha sua ideia ou objetivo a investigar definido de forma clara.

Assim que se tenha tomado a decisão de realizar uma pesquisa de cunho exploratório, deve-se pensar na elaboração de um esquema que poderá ser ou não modificado e que facilite a sua viabilidade. Para que as fases da pesquisa se processem normalmente, tudo deve ser bem estudado e planejado, inclusive a obtenção de recursos materiais, humanos e temporais.

Quando o planejamento de uma pesquisa atende a um objetivo exploratório, para descobrir verdades parciais, podemos estruturar as premissas que serão necessárias na elaboração do propósito principal. Neste caso, demonstraremos a importância da expansão dos serviços que este artigo retrata e as evidências colocadas no desenvolvimento do conteúdo previamente pesquisado. 
Existe uma diversidade de tipos de pesquisas descritivas, sejam elas no âmbito humano, sejam na esfera social, entre outras, que envolvem condições de habitação, índice de criminalidade, etc. Para Gil (2010), também são pesquisas descritivas aquelas que visam descobrir a existência de associações entre variáveis, como, por exemplo, as pesquisas eleitorais que indicam a relação entre preferência político-partidária e nível de rendimentos ou de escolaridade.

Podem ser elaboradas também características de determinada população com a finalidade de identificar possíveis relações entre variáveis. Porém há pesquisas que, embora definidas como descritivas, com base em seus objetivos, acabam servindo mais para proporcionar uma nova visão do problema, o que as aproxima das pesquisas exploratórias Gil (2010).

O estudo de caso consiste em uma modalidade de pesquisa que se aprofunda exaustivamente no estudo de um ou poucos objetos, permitindo seu amplo detalhamento. Gil (2010) refere que, de modo geral, os resultados são apresentados em aberto, ou seja, não de forma conclusiva, e sim como hipóteses. Logo, o propósito do estudo de caso não é proporcionar o conhecimento preciso de um objeto e suas características, mas sim uma visão global do problema, além de identificar possíveis fatores que são por ele influenciados ou que o influenciam.

Como podemos ver, estudos de caso que visam analisar objetos de forma global têm como princípio o aprofundamento apenas em sua delimitação, para garantir um melhor resultado através de informações de natureza qualitativa.

Para Marconi e Lakatos (2007), não há um esquema estrutural dado aprioristicamente quando de um estudo de caso qualitativo, uma vez que não se organiza em hipóteses, esquema de problemas e variáveis com antecipação. Constitui-se de detalhes de informações com diferentes técnicas de pesquisa, que, por sua vez, descrevem a complexidade de um fato, apreendendo uma determinada situação.

O método para coleta de dados neste estudo foi a pesquisa documental disponibilizada pelo Serviço Estadual de Diagnóstico por Imagem 1 (SEDI1), gerenciado pela Associação Congregação de Santa Catarina (ACSC).

Conforme Martins e Theóphilo (2009), a pesquisa documental se assemelha à pesquisa bibliográfica, todavia não levanta material editado, livros e periódicos, mas busca material que não foi editado, como cartas, memorandos, correspondências, relatórios, estudos e avaliações. Pesquisas documentais são frequentes nos estudos orientados por estratégias participativas, como o estudo de caso. 


\section{APRESENTAÇÃO E DISCUSSÃO DOS RESULTADOS}

De acordo com os estudos do Banco Mundial apresentados na tabela 1, que apresenta uma comparação de resultados de saúde entre entidades públicas OSS e tradicionais, observa-se que as OS vêm apresentando excelentes resultados com o avanço na qualidade dos serviços aos usuários do SUS.

A Organização Social de Saúde Associação Congregação Santa Catarina foi pioneira na implementação do Serviço Estadual de Diagnóstico por Imagem 1, que está localizado na zona sul da cidade de São Paulo e tem por objetivo de atender à população do SUS, através de hospitais e ambulatórios localizados em diferentes regiões da cidade que necessitam dos serviços. Por sua vez, os investimentos e as contratações de profissionais especializados para alcançar os resultados necessários tornam-se inviáveis em virtude dos altos custos, quando do seu investimento inserido em cada unidade.

Considerando um investimento através de uma central de laudos, a Telerradiologia permite laudos a distância, sem a necessidade de um médico para cada unidade de serviço, apenas os técnicos em radiologia médica são necessários in loco, uma vez que esses custos são aceitáveis e cabem dentro do orçamento.

Os exames disponíveis nesse momento para as unidades são aqueles como Ressonância Magnética, Tomografia Computadorizada, Mamografia, Ultrassonografia, Doppler e Raios-x. Apenas exames de Ultrassonografia necessitam do próprio profissional médico in loco, já os demais exames podem ser realizados pelos próprios técnicos, que, através da tecnologia dos equipamentos médicos, enviam as imagens pelo Synapse, via radiofrequência, até a central de laudos, onde há médicos radiologistas disponíveis 24 horas, todos os dias, sem qualquer parada, realizando os laudos de acordo com as prioridades previamente definidas pela gestão dos serviços, o que facilita o atendimento de urgências e emergências no menor tempo possível.

O contrato de gestão através de OSS permite a contratação de profissionais e prestadores de serviços para manutenção de equipamentos com reposição de peças no menor tempo possível, eliminando o processo de licitação. Porém é necessário obedecer ao regulamento de compras das OSS publicado no Diário Oficial da União, segundo o qual o contrato deve ser submetido a auditorias do Tribunal de Contas do Estado (TCE), Secretaria da Fazenda (SEFAZ), entre outros que regem o contrato de gestão.

A vantagem de OSS na gestão dos serviços públicos reside na agilidade da resolução dos problemas e na integração das negociações corporativas (poder de barganha) das entidades privadas que, atualmente, são estendidas para os serviços públicos. 
Para o Estado, a utilização das OSS garante uma melhor gestão financeira e o cumprimento das metas através dos indicadores de desempenho, seja em produções, seja em satisfação do usuário. Se houver o não cumprimento das responsabilidades previstas nos contratos de gestão, o Estado aplicará penalidades vigentes no contrato, garantindo ao erário público o menor prejuízo possível.

Qualquer ajuste necessário por parte do Estado junto aos serviços é negociado com as OSS através de Termos Aditivos de Reti-Ratificação, que possibilitam as adequações pertinentes às necessidades.

Para Medici e Murray (2010), o modelo OSS apresenta melhoria na qualidade dos serviços ao assegurar um atendimento mais integral aos usuários, através do cumprimento de protocolos clínicos, assistenciais e de processos, sob regime de pessoal mais capacitado. Ao mesmo tempo, essa melhoria pode ser atribuída às várias características desse modelo, como mais autonomia na seleção e contratação de seus gestores, na alocação e distribuição dos recursos orçamentários, na contratação e demissão de pessoal, entre outros fatores que envolvem o desenvolvimento através de treinamentos externos com empresas qualificadas no mercado.

Conforme as tabelas 1, 2, 3, 4, 5 e 6, as OSS proporcionam melhor vantagem para o Estado na gestão dos serviços públicos na saúde. Isso significa que a máquina pública administrada pelas entidades privadas garante maior segurança à população, no que se refere à responsabilidade das OSS em cumprir com suas obrigações sem lesar os cofres públicos. Uma vez lesada a Administração Pública, o contrato prevê sua recomposição com juros e mora, e as OSS ficam sujeitas à suspensão ou mesmo ao cancelamento de sua habilitação para gerir os serviços públicos, desfavorecendo muitas vezes a filantropia. 
Tabela 1 - Comparativo de indicadores de desempenho hospitalar

\begin{tabular}{|c|c|c|c|}
\hline Indicadores & $\begin{array}{l}\text { Modelo } \\
\text { OSS }\end{array}$ & $\begin{array}{l}\text { Administra- } \\
\text { ção Direta }\end{array}$ & $\begin{array}{l}\text { Diferen- } \\
\text { ça }(\%)\end{array}$ \\
\hline Média de altas por leito hospitalar-ano (2003) & 60 altas & 46 altas & 30,4 \\
\hline Tempo médio de permanência por leito (2003) & 3,3 dias & 5,2 dias & $-36,5$ \\
\hline $\begin{array}{l}\text { Porcentagem de cesarianas por total de partos } \\
\qquad(2003)\end{array}$ & $25,50 \%$ & $77,10 \%$ & $-66,9$ \\
\hline $\begin{array}{l}\text { Horas de trabalho médico contratadas sobre o total } \\
\text { de horas de trabalho médico de pessoal de planta } \\
\qquad(2003)\end{array}$ & 3,6 & 5,1 & $-29,9$ \\
\hline Custo médio por paciente internado (2003) & $\mathrm{R} \$ 3.300$ & $\mathrm{R} \$ 3.600$ & $-8,3$ \\
\hline $\begin{array}{l}\text { Número médio de enfermeiras qualificadas por leito } \\
\qquad(2006)\end{array}$ & 0,33 & 0,28 & 17,9 \\
\hline Número médio de funcionários por leito (2006) & 4,28 & 4,48 & $-4,5$ \\
\hline Taxa media de ocupação por leito (2006) & $80,90 \%$ & $72,10 \%$ & 12,2 \\
\hline Custo médio diário de leito de UTI (2006) & $\mathrm{R} \$ 978$ & $\mathrm{R} \$ 1.197$ & $-18,3$ \\
\hline Custo médio diário de exame de CADSCAN (2006) & $\mathrm{R} \$ 133$ & $\mathrm{R} \$ 394$ & $-66,2$ \\
\hline Custo médio de exame de câncer de mama (2006) & $\mathrm{R} \$ 33$ & $\mathrm{R} \$ 44$ & -25 \\
\hline
\end{tabular}

Fonte: La Forgia e Coutollenc (2008), para os dados de 2003; e dados da pesquisa.

Os exames disponibilizados de forma digital que esse serviço inicialmente ofereceu foram: Ressonância Magnética, Tomografia, Mamografia, Ultrassonografia, Doppler, Raios-x, entre outros que podem ser inseridos nos serviços. Podemos verificar, nas tabelas 2, 3, 4, 5 e 6, um exemplo de como, na estrutura convencional disponível para a realização do exame de raios $\mathrm{X}$ apurado em um hospital público de grande porte em São Paulo, os investimentos com esse modelo de Telerradiologia Digital favorecem os cofres públicos quando analisamos custo-benefício, conceitualmente falando, estudo de viabilidade.

$\mathrm{Na}$ tabela 3, não estão inclusos o custo do espaço por metro quadrado para armazenagem de todo o insumo necessário para a realização dos exames, despesas com pessoal da logística de distribuição, realização das compras dos insumos que são feitas através de licitações que a administração direta é obrigada a realizar, conforme a Lei Federal ${ }^{\circ}$ 8.666/93, bem como o número de técnicos de raios $\mathrm{X}$, cujo modelo convencional de exame exige um quadro maior de pessoal.

Atualmente, o hospital analisado possui um parque de equipamentos médicos para atender à população da região que necessite de exames de raios $\mathrm{X}$, conforme tabela 2 . 
Tabela 2 - Equipamentos necessários e já instalados no hospital para realização dos exames de raios X: volumetria real aproximada de 50 mil exames no terceiro trimestre de 2013

\begin{tabular}{|c|c|}
\hline Equipamentos necessários & Quantidade \\
\hline Aparelho de raios $X$ fixo & 03 \\
\hline Aparelho de raios $X$ telecomandado & 01 \\
\hline Aparelho de raios $X$ portátil & 03 \\
\hline Processadoras & 03 \\
\hline Cassetes + Chassis $18 \times 24$ & 22 \\
\hline Cassetes + Chassis $24 \times 30$ & 20 \\
\hline Cassetes + Chassis $24 \times 30-$ Mamografia & 10 \\
\hline Cassetes + Chassis $35 \times 35$ & 14 \\
\hline Cassetes + Chassis $35 \times 43$ & 32 \\
\hline
\end{tabular}

Fonte: Serviço Estadual de Diagnóstico por Imagem 1 (SEDI1-ACSC/0SS), para os dados de 2013.

Na tabela 3, é apresentada uma estimativa do consumo, em três meses, dos materiais necessários, como filmes/película de raios $\mathrm{X}$ e produtos químicos, considerados no mercado como revelador+fixador, que, por sua vez, são processados através de equipamentos conhecidos como processadoras.

Tabela 3 - Estudo estimado das despesas com insumos e manutenção (preventiva/ corretiva) com as processadoras para revelação dos filmes no período: volumetria real aproximada de 50 mil exames no terceiro trimestre de 2013

\begin{tabular}{|c|c|c|c|}
\hline Insumos Necessários & Quantidade & R\$ Unitário & R\$ Total \\
\hline Filme de raios X 18x24 (película) & 250.Cx & 56,16 & $14.040,00$ \\
\hline Filme de raios $X 24 \times 30$ (película) & 400.Cx & 95,73 & $38.292,00$ \\
\hline $\begin{array}{l}\text { Filme de raios } X 24 \times 30 \text { (película) - } \\
\text { Mamografia }\end{array}$ & 100.Cx & 224,72 & $22.472,00$ \\
\hline Filme de raios $X 35 \times 35$ (película) & 250.Cx & 158,02 & $39.505,00$ \\
\hline Filme de raios $\times 35 \times 43$ (película) & 350.Cx & 194,64 & $68.124,00$ \\
\hline $\begin{array}{l}\text { Revelador de filmes/películas (Produto } \\
\text { químico) }\end{array}$ & 200.Cx & 120,81 & $24.162,00$ \\
\hline Fixador de filmes/películas (Produto químico) & 150.Cx & 172,10 & $25.815,00$ \\
\hline $\begin{array}{l}\text { Manutenção (Preventiva/Corretiva) com as } \\
\text { Processadoras para revelação dos filmes }\end{array}$ & 04 & 700,00 & $2.800,00$ \\
\hline $\begin{array}{c}\text { Total: gastos (valor válido para o terceiro } \\
\text { trimestre de 2013) }\end{array}$ & - & - & $\begin{array}{c}R \$ \\
235.210,00 \\
\end{array}$ \\
\hline
\end{tabular}

Fonte: Serviço Estadual de Diagnóstico por Imagem 1 (SEDI1-ACSC/0SS), para os dados de 2013.

$\mathrm{Na}$ tabela 4, verifica-se o custo estimado dos investimentos com novas tecnologias que integram os equipamentos mencionados na tabela 2 , os quais vieram para substituir o uso dos insumos apresentados na tabela 3. 
Tabela 4 - Estudo de viabilidade para investimentos com a implantação de novas tecnologias que substituem os gastos demonstrados da tabela 3 ao longo do tempo: volumetria real aproximada de 50 mil exames no terceiro trimestre de 2013

\begin{tabular}{|c|c|c|c|}
\hline Equipamentos necessários & Quantidade & \$ Unitário & \$ Total \\
\hline D'EVO & 02 & $95.000,00$ & $190.000,00$ \\
\hline PROFECT CS & 02 & $77.000,00$ & $154.000,00$ \\
\hline CAPSULAX & 01 & $42.000,00$ & $42.000,00$ \\
\hline Casset $18 \times 24$ & 11 & 758,00 & $8.338,00$ \\
\hline Casset $24 \times 30$ & 10 & 901,00 & $9.010,00$ \\
\hline Casset $35 \times 35$ & 07 & $1.109,00$ & $7.763,00$ \\
\hline Casset $35 \times 43$ & 16 & $1.289,00$ & $20.624,00$ \\
\hline DRY 4000 PLUS & 01 & $19.400,00$ & $19.400,00$ \\
\hline $\begin{array}{l}\text { Hardware e software (equipamentos, } \\
\text { programas e licenças) }\end{array}$ & - & $76.015,00$ & $76.015,00$ \\
\hline Total: investimentos em dólares & - & - & $\mathrm{R} \$ 527.150,00$ \\
\hline $\begin{array}{c}\text { Total: despesas em reais (dólar do dia } \\
\text { 18/11/13: } R \$ 2,268 \text { ) }\end{array}$ & - & - & $\mathrm{R} \$ 1.195 .576,20$ \\
\hline
\end{tabular}
Fonte: Serviço Estadual de Diagnóstico por Imagem 1 (SEDI1-ACSC/0SS), para os dados de 2013.

A tabela 5 apresenta os valores médios da depreciação no trimestre, de acordo com a vida útil de cada equipamento (vide tabela 4) que o seu fabricante estima (cinco anos para alguns e dez anos para outros).

Tabela 5 - Estudo da depreciação dos investimentos no trimestre (vide valor na tabela 4) necessários para esse modelo de tecnologia: volumetria real aproximada de 50 mil exames no terceiro trimestre de 2013

\begin{tabular}{|c|c|c|c|}
\hline $\begin{array}{l}\text { Depreciação dos equipamentos } \\
\text { necessários e insumos }\end{array}$ & Quantidade & \$ Unitário & \$ Total \\
\hline D'EVO & 02 & $2.375,00$ & $4.750,00$ \\
\hline PROFECT CS & 02 & $1.925,00$ & $3.850,00$ \\
\hline CAPSULAX & 01 & $1.050,00$ & 1.050 .00 \\
\hline Casset $18 \times 24$ & 11 & 63,00 & 694,00 \\
\hline Casset $24 \times 30$ & 10 & 75,08 & 750,83 \\
\hline Casset $35 \times 35$ & 07 & 92,42 & 646,92 \\
\hline Casset $35 \times 43$ & 16 & 107,42 & $1.718,67$ \\
\hline DRY 4000 PLUS & 01 & 285,00 & 285,00 \\
\hline $\begin{array}{c}\text { Hardware e Software (Equipamentos, } \\
\text { Programas e Licenças). }\end{array}$ & - & & $3.800,00$ \\
\hline Total: despesas em dólares & - & - & $\mathrm{R} \$ 17.545,42$ \\
\hline $\begin{array}{c}\text { Total: despesas em reais (dólar do dia } \\
\text { 18/11/13: } \mathrm{R} \$ 2,268 \text { ) }\end{array}$ & - & - & $\mathrm{R} \$ 39.793,01$ \\
\hline
\end{tabular}

Fonte: Serviço Estadual de Diagnóstico por Imagem 1 (SEDI1-ACSC/0SS), para os dados de 2013 
Na realização de um exame de raios X, é necessário, em alguns casos, o uso de outros insumos que não foram mencionados neste estudo, pois foram considerados irrelevantes. Além disso, a mão de obra também não está incluída no cálculo, por se tratar de custo baseado em atividade. Este estudo apenas demonstra os gastos com insumos, como se pode verificar na tabela 6 , que apresenta um comparativo entre o modelo convencional e o modelo com a integração das novas tecnologias. Além disso, a pesquisa demonstra o impacto direto das OSS no aumento da realização de exames, cujo tempo da realização, em muitos casos, reduz em média $50 \%$ e incide diretamente na saúde do paciente, por receber uma menor dosagem de radiação.

Tabela 6 - Estudo comparativo dos gastos no modelo convencional (vide tabela 3$) \times$ modelo com novas tecnologias (vide tabela 5): volumetria real aproximada de 50 mil exames no terceiro trimestre de 2013

\begin{tabular}{|c|c|c|c|}
\hline Indicadores & $\begin{array}{c}\text { Despesas } \\
\text { com modelo } \\
\text { convencional (R\$) }\end{array}$ & $\begin{array}{c}\text { Despesas } \\
\text { com novas } \\
\text { tecnologias } \\
(\mathrm{R} \$)\end{array}$ & Diferença (\%) \\
\hline $\begin{array}{c}\text { Insumos } \\
\text { Manutenção (Preventiva/ }\end{array}$ & $235.210,00$ & 0,00 & 100 \\
\hline $\begin{array}{c}\text { Corretiva) com as } \\
\text { Processadoras para revelação } \\
\text { dos filmes }\end{array}$ & $8.440,00$ & $8.440,00$ & 50 \\
\hline $\begin{array}{l}\text { Manutenção (Preventiva/ } \\
\text { Corretiva) com as novas } \\
\text { tecnologias }\end{array}$ & 0,00 & $23.000,58$ & 100 \\
\hline Depreciação dos equipamentos & 0,00 & $39.793,01$ & 100 \\
\hline $\begin{array}{l}\text { Prestação de Serviços (Links, } \\
\text { PACS e demais) }\end{array}$ & 0,00 & $48.072,00$ & 100 \\
\hline Total das despesas & $\mathrm{R} \$ 243.650,00$ & R\$ 119.305,59 & 51,03 \\
\hline \multicolumn{2}{|c|}{$\begin{array}{l}\text { Total da Economia estimada por trimestre com o } \\
\text { novo modelo }\end{array}$} & $124.344,41$ & \\
\hline
\end{tabular}

Fonte: Serviço Estadual de Diagnóstico por Imagem 1 (SEDI1-ACSC/0SS), para os dados de 2013.

A análise comparativa apresentada na tabela 6 demonstra claramente um retorno sobre o investimento a partir de 2,4 anos. Obviamente que esse é um tempo máximo, em que não está incluída a redução de custos com pessoal técnico e de logística, desuso do espaço (almoxarifado) por metro quadrado para armazenagem dos insumos, que pelo volume necessita de pelo menos $30 \mathrm{~m}^{2}$, e também o aumento em $30 \%$, no mínimo, dos exames. 


\section{CONSIDERAÇÕES FINAIS}

A pesquisa apresentada neste artigo teve por objetivo demonstrar que a administração da saúde pública no Brasil, mais especificamente em São Paulo, adotou um modelo de gestão que veio a complementar o avanço na qualidade dos serviços aos usuários do Sistema Único de Saúde (SUS), denominado Organização Social de Saúde.

Os indicadores das tabelas 1 a 6 demonstram o melhor custo-benefício aos cofres públicos e, mais ainda, a grande preocupação com a qualidade de diagnóstico à população, no menor tempo possível, visando a um atendimento humanizado e diminuindo as grandes filas de espera, seja no agendamento, seja na própria realização dos exames. Isso se deve à tecnologia inovadora apresentada neste artigo, em que o usuário, ao se submeter à realização dos exames de raios $\mathrm{X}$, expõe-se no menor tempo possível ao equipamento que emite radiação, diminuindo, assim, o risco de prejudicar a sua saúde, sem contar que a extinção do uso de insumos por esse modelo favorece o meio ambiente, o que se reflete na qualidade de vida das pessoas de um modo geral.

O modelo SEDI1-ACSC/OSS como Organização Social de Saúde representa um melhor custo-benefício à Administração Pública, permitindo, assim, uma gestão profissional que favorece a evolução dos serviços, através de profissionais qualificados e treinados continuamente. Diante do não cumprimento das atividades e metas pré-estabelecidas, as OSS têm total autonomia em processos de rescisão contratual na prestação dos serviços, previstos no regime de contratação na Consolidação de Leis do Trabalho (CLT), sem que haja qualquer outro meio burocrático que venha a interferir ou mesmo impedir a gestão, que ao final prejudique os usuários (pacientes) do SUS.

Pode-se, assim, incentivar a continuidade da pesquisa neste segmento, favorecendo os investimentos em outros estados do Brasil e, ainda mais, em outros exames utilizados por meio de imagens diagnósticas. Recomenda-se, cada vez mais, a exploração dessas tecnologias que integram os processos burocráticos para melhor controle estatístico, com o objetivo de baratear gradativamente os custos desses investimentos, permitindo o alcance dos usuários que acabam não tendo acesso aos serviços, por estarem em cidades deficitárias que hoje o Brasil possui em sua escala demográfica.

Outra sugestão de pesquisa voltada a esse segmento é a Telepatologia, que recorre à utilização das telecomunicações para permutar imagens estatísticas ou dinâmicas de lâminas ou órgãos em estudo anatomopatológico de casos e resolução de diagnósticos. Tal pesquisa poderia contribuir para o meio acadêmico, podendo favorecer a comunidade e a ciência na busca de grandes avanços na medicina. 


\section{REFERÊNCIAS}

Conselho Federal de Contabilidade (1999). Resolução n. 836, 22 de fevereiro de 1999. Aprova a NBC T11- IT - 03 Fraude e Erro. Recuperado de http://portalcfc.org.br/legislacao/

Brasil. (1988). Constituição da República Federativa do Brasil. Recuperado de http://www.planalto.gov.br/ccivil_03/Constituicao/Constituicao.htm

(1990). Lei $n^{\circ} 8.080$, de 19 de setembro de 1990. Dispõe sobre as condições para a promoção, proteção e recuperação da saúde, a organização e o funcionamento dos serviços correspondentes e dá outras providências. Recuperado de http://portal.saude.gov.br/portal/arquivos/pdf/lei8080.pdf . (1993). Lei n 8.666, de 21 de junho de 1993. Regulamenta o art. 37, inciso XXI, da Constituição Federal, institui normas para licitações e contratos da Administração Pública e dá outras providências. Recuperado de http:// www.planalto.gov.br/ccivil_03/leis//8666cons.htm

(1995). Plano Diretor da Reforma do Aparelho do Estado. Presidência da República, Câmara da Reforma do Estado, Ministério da Administração Federal e Reforma do Estado, Brasília.

(1998). Lei n ${ }^{\circ}$ 9.637, de 15 de maio de 1998. Dispõe sobre a qualificação de entidades como organizações sociais, a criação do Programa Nacional de Publicização, a extinção dos órgãos e entidades que menciona e a absorção de suas atividades por organizações sociais, e dá outras providências. Recuperado de http://www.planalto.gov.br/ccivil_03/leis/19637.htm

Bresser-Pereira, L. C. (1996, Janeiro/Abril). Da Administração Pública Burocrática à Gerencial. Revista do Serviço Público, 47(1). Trabalho apresentado ao Seminário sobre Reforma do Estado na América Latina, organizado pelo Ministério da Administração Federal e Reforma do Estado e patrocinado pelo Banco Interamericano de Desenvolvimento.

(1998). Reforma do Estado para a cidadania: A reforma gerencial brasileira na perspectiva internacional. São Paulo: Editora 34.

Ferreira Júnior, V. C. (2003, Março/Abril). Gerenciamento de hospitais estaduais paulista por meio de organizações sociais de saúde. Revista de Administração Pública, 37(2), 243-264.

Gil, A. C. (2010). Como elaborar projetos de pesquisas. (5. ed.). São Paulo: Atlas. La Forgia, G. \& Couttolenc, B. (2008). Desempenho de hospitais no Brasil: A busca de excelência. Washington, D.C.: Banco Mundial.

Marconi, M. A. \& Lakatos, E. M. (2007). Metodologia científica. (5. Ed.). São Paulo. 
Martins, G. A. \& Theóphilo, C. R. (2009). Metodologia da investigação científica para Ciências Sociais Aplicadas. (2. ed.). São Paulo: Atlas.

Médici, A. \& Murray, R. (2003). Desempenho de hospitais e melhorias na qualidade de saúde em São Paulo (Brasil) e Maryland (EUA). Washington: The World Bank. Recuperado de http://siteresources.worldbank.org/INTLAC/Resources/257803-1269390034020/EnBreve_156_Web_Port.pdf

São Paulo. (1998). Lei Complementar n 846, de 4 de junho de 1998. Dispõe sobre a qualificação de entidades como organizações sociais e dá outras providências. Recuperado de http://www.al.sp.gov.br/repositorio/legislacao/lei\%20complementar/1998/lei\%20complementar\%20n.846,\%20de\%20 04.06.1998.htm 